\title{
Tibial hemimelia
}

INSERM

\section{Source}

INSERM. (1999). Orphanet: an online rare disease and orphan drug data base. Tibial

hemimelia. ORPHA:93322

Tibial hemimelia is a rare congenital anomaly characterized by deficiency of the tibia with a relatively intact fibula. 